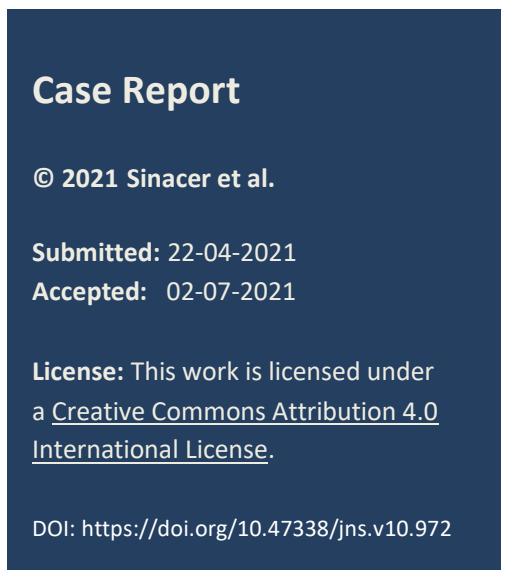

\title{
Congenital Spigelian hernia in a neonate associated with several anomalies: A case report
}

Samira Sinacer, ${ }^{* 1,2}$ Bilal Zakaria Semari, ${ }^{2}$ Soumia Khemari, ${ }^{2}$ Ahlem Kharchi, ${ }^{2}$ Assia Haif,, ${ }^{1,2}$ Zineddine Soualili, $^{1,2}$

1 Department of Pediatric Surgery, Laboratory of Pediatric Surgery Applied, Ferhat Abbas Sétif University 1Algeria

2 Department of Pediatric Surgery, University Hospital Center of SETIF, Algeria

Correspondence*: Dr. Samira Sinacer, Department of Pediatric Surgery, Laboratory of Pediatric Surgery Applied, Children's and Mother's Hospital of Sétif Algeria. E-mail: sinacer3samira@gmail.com

\begin{tabular}{ll}
\hline KEYWORDS & ABSTRACT \\
$\begin{array}{l}\text { Spigelian hernia, } \\
\text { Anal stenosis, } \\
\text { Cryptorchidism, }\end{array}$ & $\begin{array}{l}\text { Background: Spigelian hernia (SH) is a rare entity characterized by a defect of the anterior } \\
\text { abdominal wall located along the Spigelian line, it may be congenital or acquired. } \\
\text { Association with other anomalies is worth reporting. } \\
\text { Case presentation: A 22-day-old male newborn was admitted with strangulated right } \\
\text { inguinal hernia and operated on emergently. Clinical examination also revealed a Spigelian } \\
\text { hernia in the left lower abdominal quadrant with bilateral cryptorchidism, associated with } \\
\text { polydactyly of the small right finger and anal stenosis. At surgery, the SH contained a part of } \\
\text { the small intestine and the ipsilateral undescended testis. } \\
\text { Conclusion: Pediatric SH is rare, but its association with undescended ipsilateral testis is } \\
\text { frequent. Other abnormalities can be concomitant to this association. }\end{array}$ \\
\hline
\end{tabular}

\section{INTRODUCTION}

The SH is defined by the protrusion of an organ or fat through a congenital or acquired defect in the semilunar line (the aponeurosis of the transverse abdominal muscle); it is rarely seen in children and extremely uncommon in neonate where it is suspected to be congenital.[1-3] Several congenital associated anomalies are well-known especially the association of ipsilateral undescended testis and $\mathrm{SH}$ (Raveenthiran syndrome) but the relationship between them is still debated.[2] Herein we report a case of Raveenthiran syndrome associated with other anomalies.

\section{CASE REPORT}

A 22-day-old male neonate born at full-term with Csection delivery, weighing 3.3 kilograms at birth and 4 kilograms at presentation; her mother had type 1 diabetes mellitus. At presentation, there was an irreducible right inguinal swelling along with an active chest infection. Physical examination revealed a strangulated inguinal hernia, associated with a palpable mass on the left lower abdominal quadrant that was spontaneously reducible and non-tender with bilateral undescended testis (Fig.1A). There was also polydactyly of the right hand along with anal stenosis. The abdominal radiograph plain film noted small gut air shadows coming out of the abdominal wall (Fig.1B) and the ultrasonography revealed an abdominal wall defect.

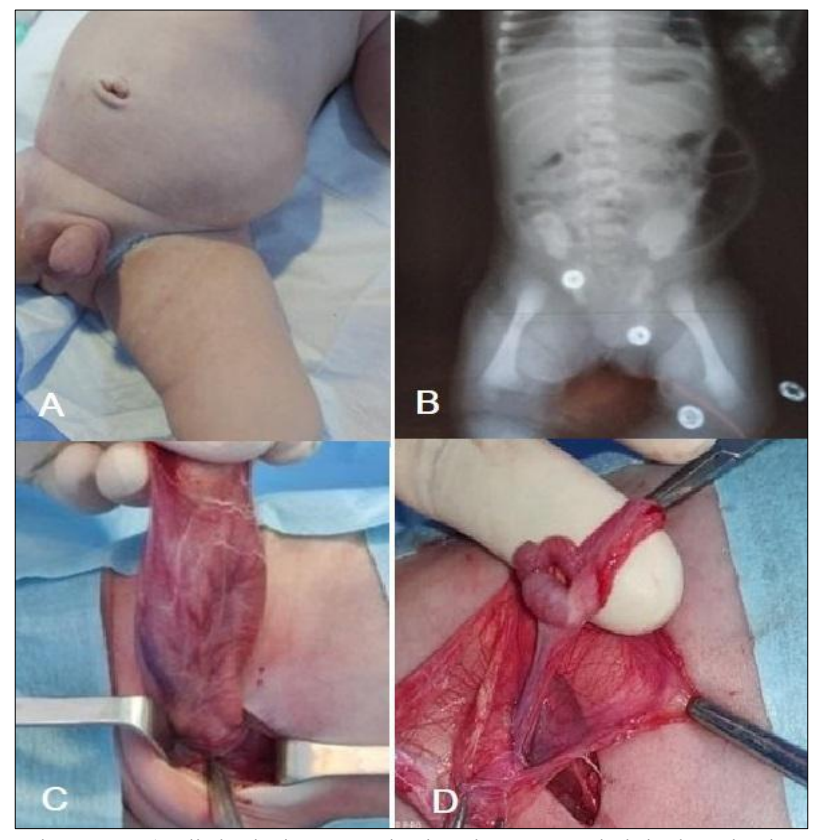

Figure 1: A) Clinical photograph showing $\mathrm{SH}$ and right inguinal swelling. B) X-ray of the baby showing gut gas shadow in the $\mathrm{SH}$. C) Sac of the SH. D) Testis is being separated from the sac. 
The diagnosis of a strangulated right inguinal hernia was made, and it was emergently treated through right inguinal herniotomy along with right orchiopexy. Chest infection was also treated. On the 7 th postoperative day, the Spigelian hernia was explored by a transverse incision over the protrusion, the hernial sac was located between the external oblique aponeurosis and the internal oblique muscle (Fig.1C), the orifice diameter was approximately $1.5 \mathrm{~cm}$, and the hernia sac contained a part of the small intestine and the left testis. After separating the testicular pedicle, (Fig.1D) the sac was excised, and the fascial defect was closed with a non-absorbable suture. The child was discharged home the next day. The treatment for anal stenosis was postponed as currently there was no difficulty in defecation.

\section{DISCUSSION}

$\mathrm{SH}$ is an uncommon disease both in adults and in children and it is one of the rarest types of abdominal hernia in neonates. Scopinaro in 1935 was the first to report a lateral ventral hernia in children.[4] Although adult hernias are considered to be acquired because of trauma or increased intraabdominal pressure, pediatric cases have no evident cause and are supposed to be congenital.[5] In our case, the age of the child and the presence of SH synchronously with other congenital anomalies argues strongly for a congenital etiology, despite he had also a factor of increasing intraabdominal pressure which is the anal stenosis, while maternal diabetes is not known to be a risk factor.

Al-Salem found that $35 \%$ of pediatric $\mathrm{SH}$ are associated with other congenital anomalies.[6] Such as undescended testis, inguinal hernia, umbilical hernia, hypospadias, congenital diaphragmatic hernia, bladder, and cloacal exstrophy. A case of anorectal malformation associated with $\mathrm{SH}$ has also been reported as found in the index case.[2]

The cryptorchidism with SH (Raveenthiran syndrome) is particularly a well-recognized entity and this association is found in up to $75 \%$ of male infants. [ 7,8$]$ The testis is found in the sac in most cases as reported in our case.[5,8] The discussion about the relationship between the two anomalies is still open and there is a controversy about the pathogenic mechanism of this association; some authors hypothesize that the $\mathrm{SH}$ is the cause of undescended testis; they argued that the existence of SH alters the intraabdominal pressure which is necessary for testicular descent as it happens in gastroschisis and Prune Belly syndrome.[6,8] Unlike other authors,

\section{REFERENCES}

1. Shea B, Fasano G, Cohen IT. Pediatric Spigelian hernia: a case report and review of the literature. J Pediatr Surg Case Rep. 2017; 100:7-9.
Raveenthiran argues that ectopic testis is the primary pathology, and it leads to the formation of $\mathrm{SH}$ by dragging a peritoneal sac along with it.[2]

The defect is often unilateral and the unilateral entity is most common, but the bilateral cases have also been reported in neonates.[9]

The diagnosis of $\mathrm{SH}$ is often difficult because there are no characteristic symptoms. It was not the case in our patient because the physical examination was conclusive but in difficult cases, the ultrasonography may be helpful. Once diagnosed, repair of the hernia is mandatory in order to prevent incarceration with possible strangulation because the orifice is generally small $(0.5-2 \mathrm{~cm})$ and the risk of strangulation is estimated to be $10 \%$.[8] Our patient was operated on early fearing this risk, the reason for not repairing Spigelian hernia at the time of inguinal herniotomy was due to prolong anesthesia risk secondary to active chest infection.

The treatment of Spigelian hernia is exclusively surgical, SH can be repaired using the open approach with a primary suture repair, or by placing mesh when the defect is larger or when there is a risk of recurrence. Oblique or transverse incisions over the hernia are the most common approaches. the median incision is recommended if there is no palpable hernia or hernia orifice.[10]

The laparoscopic approach is becoming widely used because of its several benefits such: reduced hospital stay, quicker recovery, and fewer infections and parietal complications. It also aids in correct diagnosis in difficult cases, however, open surgery is still considered the technique of choice in children.[9] There are no significant advantages in the laparoscopic approach compared to open surgery according to Moreno.[11]

In conclusion, despite its rarity in the pediatric population, $\mathrm{SH}$ required special attention and the search for associated anomalies is mandatory especially the ipsilateral undescended testis.

\section{Acknowledgements: Nil \\ Conflict of Interest: Authors have no conflict of interest. \\ Source of Support: Nil}

Consent to Publication: Author(s) declared taking informed written consent for the publication of clinical photographs/material (if any used), from the legal guardian of the patient with an understanding that every effort will be made to conceal the identity of the patient, however it cannot be guaranteed.

Author Contributions: Author(s) declared to fulfil authorship criteria as devised by ICMJE and approved the final version.

2. Raveenthiran V. Congenital Spigelian hernia with cryptorchidism: probably a new syndrome. Hernia. 2005; 9:378-80. 
3. Koutaba E, Mandavo CM, Latou NM, Moukala CN, Mieret JC, Ibara BA. [Spiegel's Hernia in Children: About a Case at Brazzaville University Hospital]. Health Sci Dis. 2016; 17. [Article in French]

4. Scopinaro A. Hernia on spigels semilunar line in a newborn. Semana Med. 1935; 1:284-5.

5. Rushfeldt C, Oltmanns G, Vonen B. Spigeliancryptorchidism syndrome: a case report and discussion of the basic elements in a possibly new congenital syndrome. Pediatr Surg Int. 2010; 26:939-42.

6. Al-Salem AH. Congenital Spigelian hernia and cryptorchidism: cause or coincidence? Pediatr Surg Int. 2000; 16:433-6.

7. Jones BC, Hutson JM. The syndrome of Spigelian hernia and cryptorchidism: a review of paediatric literature. J Pediatr Surg. 2015; 50:325-30.
8. Durham MM, Ricketts RR. Congenital Spigelian hernias and cryptorchidism. J Pediatr Surg. 2006; 41:1814-7.

9. Ali SW, Bibi G. Congenital bilateral Spigeliancryptorchidism syndrome? A case report. APSP J Case Rep. 2019; 10:1.

10. Spinelli C, Strambi S, Pucci V, Liserre J, Spinelli G, Palombo C. Spigelian hernia in a 14-year-old girl: a case report and review of the literature. Eur J Pediatr Surg Rep. 2014; 2:58.

11. Moreno-Egea A, Carrasco L, Girela E, Martín JG, Aguayo $\mathrm{JL}$, Canteras M. Open vs laparoscopic repair of spigelian hernia: a prospective randomized trial. Arch Surg. 2002; 137:1266-8. 